\title{
Effect of vehicular pollution on mental performance of school going children (11-15 years) in a North Indian city
}

\section{MADHULIKA SHARMA AND VEENA NIGAM}

Article Chronicle : Received : 16.10.2015;

Revised :

22.10.2015;

Accepted :

08.11.2015

Key Words :

Vehicular pollution, Mental performance, School-going children
ABSTRACT : School going children who spend most of their day time in school and playing outside are one of the most vulnerable towards deleterious and hazardous effects of environmental pollutants. In the following study an attempt was made to study the effect of exposure to vehicular pollution on the mental performance of school going children in Kanpur city. Initially the city was divided into four areas; highly polluted, moderately polluted, low polluted and unexposed/ negligible pollution areas on the basis of traffic congestion on roads. The traffic volume data of various areas was collected to measure the vehicular pollution of these areas. Out of these four areas, 320 children of 11-15 years, 80 children ( 40 boys and 40 girls) from two roadside schools of each area were selected using random cum purposive sampling method. The mental performance of children was measured in terms of forward immediate memory, recognition ability and vigilance using a part of Bhatia battery test, embedded figure test and bourdan wiersma vigilance test, respectively. The data collected was analyzed using ANNOVA test. A significant difference was found between the forward Immediate memory, recognition ability and vigilance of children of exposed areas and unexposed areas (F-ratio; 54.87, 70.98 and 16.65 , respectively).

HOW TO CITE THIS ARTICLE : Sharma, Madhulika and Nigam, Veena (2015). Effect of vehicular pollution on mental performance of school going children (11-15 years) in a North Indian city. Asian J. Environ. Sci.,10(2): $126-132$.

Author for correspondence :

\section{MADHULIKA}

SHARMA

Department of Home

Science, Juhari Devi Girls

P.G. College, KANPUR

(U.P.) INDIA

See end of the article for

Coopted authors' 